\title{
TO DETERMINE THE EFFECTIVENESS OF REMINDING PATIENTS IN MAINTAINING GOOD ORAL HYGIENE VIA WHATSAPP MESSAGES COMPARED WITH THE CONVENTIONAL TEXT MESSAGING
}

\author{
SAMEER AHMAD MALIK ${ }^{a 1}$, RAJA KODOPI ${ }^{b}$, S.M. LAXMIKANTH ${ }^{c}$ AND POOJA GUDALA ${ }^{d}$ \\ abcd Department of Orthodontics and Dentofacial Orthopedics, AECS Maaruti College of Dental Sciences and Research Centre, Bangalore, \\ India
}

\section{ABSTRACT}

To determine the effectiveness of reminding patients in maintaining good oral hygiene via Whatsapp messages compared with the conventional text messaging. In this randomized, controlled clinical trial, thirty four orthodontic patients were assigned to two groups of Whatsapp and text message. Patients in both the groups were reminded twice each week for 5 weeks and one reminder message for 8 weeks thereafter. Oral hygiene compliance was measured using bleeding index (BI), modified gingival index (MGI), and plaque index (PI) at the start (T0), at 5 weeks after baseline (T1), and at 8 weeks after the start (T2). The Whatsapp group had highly significant lower BI, MGI, and PI scores than the text message group at T2. The use of Whatsapp messaging over the text message reminders, sent by the orthodontist, was more effective for maintaining oral hygiene in orthodontic patients.

KEYWORDS: Oral hygiene; Whatsapp; Text message; Orthodontics; Plaque

Oral hygiene compliance is important during orthodontic treatment. It is in control of the patient. Plaque accumulation can lead to detrimental effects to the periodontium, like recession, pocket formation, overgrowth, and subsequent bone loss. (Skidmore et al., 2006) (Derks et al., 2007) (Bollen et al., 2008) (Zachrisson and Zachrisson, 1972) (Alstad and Zachrisson, 1979) (Zachrisson and Alnaes, 1973) (Burket, 1963) (Atack et al., 1996) (Schluger, 1968) Previous studies have shown a decline in oral hygiene after bonding of brackets. At the later stage of treatment in $20^{\text {th }}$ to $25^{\text {th }}$ week, an improvement was observed. Some studies have also demonstrated that oral hygiene problems are maximum at the end of orthodontic treatment. It is rather a challenge to obtain a sustained acceptable oral hygiene during orthodontic. (Cantekin et al., 2011)

In healthcare provider services, it has been shown that message reminders could be an effective tool for behavioural change and disease prevention. (Fjeldson et al., 2009) (Cole-Lewis and Kershaw, 2010) A 2009 systematic review in the medical field demonstrated positive behaviour changes in 13 of the 14 studies that met the authors' inclusion criteria, including smoking cessation therapy, diabetes self-management, and anti-obesity behaviour (Fjeldsoe et al., 2009)

Text message is effective in reducing missed appointments. Follow-up text message sent from an orthodontic clinic following initial bonding resulted in patient's lower levels of self-reported pain. (Almog et al., 2003) (Roth et al., 2004) (Can et al., 2003) (Foley and O'Neill, 2009) Another study showed that text message reminders to the patients or parents were shown to be an effective way to improve oral hygiene in these patients. (Keith et al., 2013). Further, with the introduction of online text messaging through Whatsapp, it has become lot easier to communicate with the patient and a graphic content explaining the methods to maintain oral hygiene can also be sent along with the message reminder.

The aim of this study was to determine the effectiveness of reminding patients in maintaining good oral hygiene via Whatsapp messages compared with the conventional text messages sent to them weekly encouraging them about oral hygiene compliance.

\section{MATERIALS AND METHODS}

This randomized clinical trial was done on a sample of 34 orthodontic patients. Subjects were required to be in active treatment with fixed appliances in both arches, between the ages of 17 and 24, with no significant medical history. Patient must have worn the appliance for at least 1 month and have at least 9 months remaining orthodontic treatment and should possess a smart phone mobile cellular device with a working internet. 
The Whatsapp message group was composed of 7 boys and 10 girls, while the text message group included 6 boys and 11 girls. The whatsapp group was sent two messages each week at an interval of three days along with a motivating graphic explaining use and advantage of wearing elastics while as text message group was sent two standard text messages each week for the duration of the study using Practo which is patient management software. Subjects were blinded as to group status and were not made aware that there were two categories of whatsapp and text message groups as a part of the study.

After the bonding of appliance, all the patients were given oral hygiene instruction and a oral hygiene kit including a toothbrush, inter proximal brush and a flouride mouthwash and an oral hygiene instruction chart was given. At this initial time (T0) readings of the Ramfjord teeth (maxillary right first molar, maxillary left central incisor, maxillary left first premolar, mandibular left first molar, mandibular right central incisor, and mandibular right first premolar) were recorded for bleeding index (BI), modified gingival index (MGI), and plaque index (PI). Same examiner conducted the examnation for all subjects to avoid any inter examiner bias.

The BI described by Saxton and van der Ouderaa (26) was done by probing the mesio-buccal, buccal and disto-buccal aspects of the gingival sulci of the Ramfjord teeth. BI scoring is described in Table 1. (Saxton and van der Ouderaa, 1989) The MGI of the buccal marginal gingiva for all Ramfjord teeth was scored as in Table 2. The PI measurement was recorded for buccal surface of Ramfjord teeth according to the Turesky modification on the Quigley-Hein index scoring system as in in Table 3 (Quigley and Hein, 1962).

Table 1: Bleeding Index (BI) Measurements

\begin{tabular}{|c|l|}
\hline Score & \multicolumn{1}{|c|}{ Presentation } \\
\hline 0 & Absence of bleeding after 30 seconds \\
\hline 1 & Bleeding observed after 30 seconds \\
\hline 2 & Immediate bleeding \\
\hline
\end{tabular}

Table 2: Modified Gingival Index (MGI) Measurements

\begin{tabular}{|c|c|}
\hline Score & \multicolumn{1}{|c|}{ Presentation } \\
\hline 0 & Absence of inflammation \\
\hline 1 & Mild inflammation (marginal or papillary \\
\hline
\end{tabular}

\begin{tabular}{|c|l|}
\hline & unit) \\
\hline 2 & $\begin{array}{l}\text { Mild inflammation (entire marginal and } \\
\text { papil- lary unit) }\end{array}$ \\
\hline 3 & Moderate inflammation \\
\hline
\end{tabular}

Table 3: Plaque Index (PI) Measurements

\begin{tabular}{|c|l|}
\hline Score & \multicolumn{1}{|c|}{ Presentation } \\
\hline 0 & No plaque \\
\hline 1 & $\begin{array}{l}\text { Discontinuous band of plaque at gingival } \\
\text { margin }\end{array}$ \\
\hline 2 & $\begin{array}{l}\text { Up to 1-mm continuous band of plaque at } \\
\text { gingival margin }\end{array}$ \\
\hline 3 & $\begin{array}{l}\text { Band of plaque wider than } 1 \mathrm{~mm} \text { but less } \\
\text { than } 1 / 3 \text { of surface }\end{array}$ \\
\hline 4 & $\begin{array}{l}\text { Plaque covering between } 1 / 3 \text { and } 2 / 3 \text { of } \\
\text { surface }\end{array}$ \\
\hline
\end{tabular}

The text message group was sent a message twice a week for 5 weeks (totaling 10 texts) as a reminder and encouragement to practice good oral hygiene. The contents of the text message were: "A healthy smile increases your face value. Do remember to maintain a good health of your teeth and gums by following the instruction card in your oral health kit. We appreciate your effort in doing so. See you soon". The text message was sent using Practo Software (Figure 1). A same text was sent to whatsapp group however with an added graphic image (Figure 2). After the 4 weeks period, both groups were reevaluated. Following the first time point (T1), both the groups received a message once a week for 10 weeks. At this second time period (T2), both groups were reevaluated again. BI, MGI, and PI scores were compared between groups for all three time points using paired samples t-test and one way analysis of variance (ANOVA). The significance level was set at $P<.5$ (significant) and $P<$ .001 (highly significant). SPSS 22 software under windows 10 was used for all statistical analysis.

\section{RESULTS}

34 patients were randomly assigned to the whatsapp group and the text message group. There were 21 females and 13 males with a mean age of 20.2 years, ranging from 17 to 23 years of age. Table 4 shows the descriptive statistics of BI, MGI, and PI for both groups at the three time points. There were no differences in scores between the groups at baseline $(P<.5)$ (Table 5). At T1, 
there were no BI, MGI, or PI differences between the groups either. At T2, the whatsapp group had a significant lower BI $(P=.000)$, MGI $(P=.000)$, and PI $(P=.000)$ scores. Within the groups, BI, MGI, and PI highly improved over time in the whatsapp message group $(P=$
$.000)$. Within the text message group, BI values degraded over time $(P=.001)$ while MGI, and PI showed no significant change. The changes with time points in BI, MGI, and PI are in Figures 1-3, respectively.

Table 4: Descriptive statistics of BI, MGI, and PI for text message and control groups

\begin{tabular}{|c|c|c|c|c|}
\hline Time interval & $\begin{array}{c}\text { Whatsapp group } \\
\text { mean }\end{array}$ & $\begin{array}{c}\text { Whatsapp group } \\
\text { SD }\end{array}$ & $\begin{array}{c}\text { Text message } \\
\text { group mean }\end{array}$ & $\begin{array}{c}\text { Text message } \\
\text { group SD }\end{array}$ \\
\hline \multicolumn{5}{|c|}{ BI } \\
\hline $\mathrm{T} 0$ & 1.47 & .624 & 1.24 & .664 \\
\hline $\mathrm{T} 1$ & 1.29 & .470 & 1.53 & .514 \\
\hline $\mathrm{T} 2$ & .29 & .470 & 2.00 & .500 \\
\hline \multicolumn{5}{|l|}{ MGI } \\
\hline $\mathrm{T} 0$ & 3.12 & .781 & 2.71 & .920 \\
\hline $\mathrm{T} 1$ & 2.47 & .624 & 2.82 & .809 \\
\hline $\mathrm{T} 2$ & .65 & .702 & 3.35 & .702 \\
\hline \multicolumn{5}{|c|}{ PI } \\
\hline $\mathrm{T} 0$ & 3.00 & .866 & 2.71 & .849 \\
\hline $\mathrm{T} 1$ & 2.59 & .795 & 2.94 & .659 \\
\hline $\mathrm{T} 2$ & .59 & .618 & 3.29 & .588 \\
\hline
\end{tabular}

Table 5: Paired samples t test

\begin{tabular}{|c|c|c|c|c|c|c|c|c|}
\hline \multirow[t]{3}{*}{ Pairs } & \multicolumn{5}{|c|}{ Paired Differences } & \multirow[t]{3}{*}{$\mathbf{t}$} & \multirow[t]{3}{*}{ df } & \multirow{3}{*}{$\begin{array}{l}\text { Sig. (2- } \\
\text { tailed) }\end{array}$} \\
\hline & \multirow[t]{2}{*}{ Mean } & \multirow[t]{2}{*}{$\begin{array}{l}\text { Std. } \\
\text { devia- } \\
\text { tion }\end{array}$} & \multirow[t]{2}{*}{$\begin{array}{l}\text { Std. } \\
\text { error } \\
\text { mean }\end{array}$} & \multicolumn{2}{|c|}{$\begin{array}{l}95 \% \text { confidence } \\
\text { interval of the } \\
\text { difference }\end{array}$} & & & \\
\hline & & & & Lower & Upper & & & \\
\hline BI T0 & .235 & .664 & .161 & -.106 & .577 & 1.461 & 16 & .163 \\
\hline BI T1 & -.235 & .562 & .136 & -.524 & .054 & -1.725 & 16 & .104 \\
\hline BI T2 & -1.706 & .470 & .114 & -1.947 & -1.464 & -14.976 & 16 & $.000 *$ \\
\hline MGI T0 & .412 & 1.004 & .243 & -.104 & .928 & 1.692 & 16 & .110 \\
\hline MGI T1 & -.353 & .786 & .191 & -.757 & -.051 & -1.852 & 16 & .083 \\
\hline MGI T2 & -2.706 & .920 & .223 & -3.179 & -2.233 & -12.133 & 16 & $.000 *$ \\
\hline PI T0 & .294 & 1.047 & .254 & -.244 & .832 & 1.159 & 16 & .264 \\
\hline PI T1 & -.353 & .862 & .209 & -.796 & -.090 & -1.689 & 16 & .111 \\
\hline PI T2 & -2.706 & .470 & .114 & -2.947 & -2.464 & -23.754 & 16 & $.000 *$ \\
\hline
\end{tabular}

\section{DISCUSSION}

This study examined the effect of whatsapp messages over text message as a reminder, which was sent to two group of patients on their oral hygiene compliance. WhatsApp is an app that allows to send a messages to someone over the internet. This differs from standard SMS messaging, which sends texts over the mobile network. It is possible to send and receive WhatsApp messages on smartphones, tablets, laptops and desktop computers, as long as there is a downloaded WhatsApp software. The advantage of using WhatsApp over texting is that it can be cheaper, depending on the situation and the data package. Moreover, it allows to send audiovisual aids like pictures and videos along with the text which is more effective in delivering a message. The use of AV aids regarding oral health is uncommon in India. AV aid provides a comprehensive, self-directed, evidence-based approach to the promotion of oral health.

Eppright et al.,, 2014 found that sending text messages to the parents was effective for improving oral 
hygiene compliance in orthodontic patients, and Bowen et al.,, 2015 found that text messages reminding and encouraging good oral hygiene resulted in a less measurable surface area of plaque over time. According to Lally et al.,, it takes an average time of 66 days to turn a behavior into an automatic habit. This lag time in habit formation may explain why differences in oral hygiene measures were not seen at $\mathrm{T} 1$, which was 4 weeks after baseline.

Further, with the widespread use of smart phones, the use of text messaging is becoming obsolete and at instances a received text message is commonly ignored or overlooked. Also, the mobile data packages in India have become very cost effective over the past few years and this has further tipped the balance in favour of online messaging services, especially whatsapp. This trend is more commonly seen in youngsters and this is the age group that we commonly see as patients in orthodontic practise. MGI, and PI

In the study the outcome was assessed using BI,

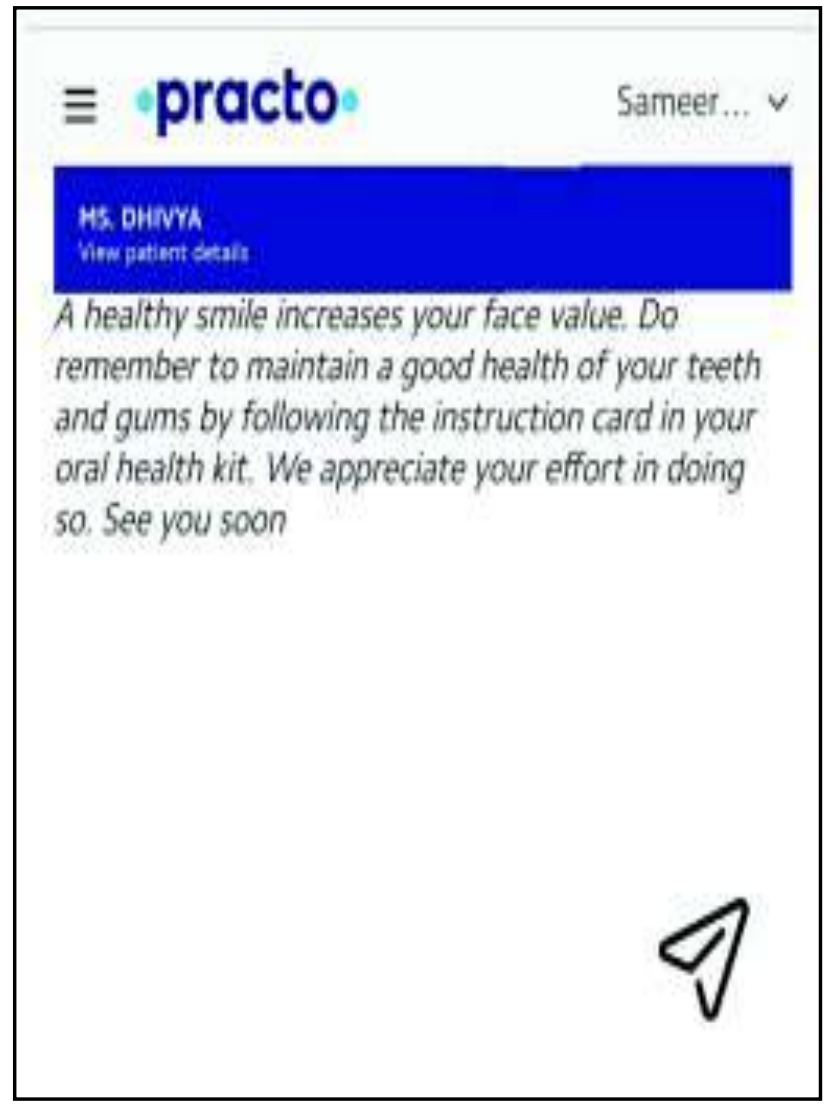

Figure 1: Treatment response for BI over time.

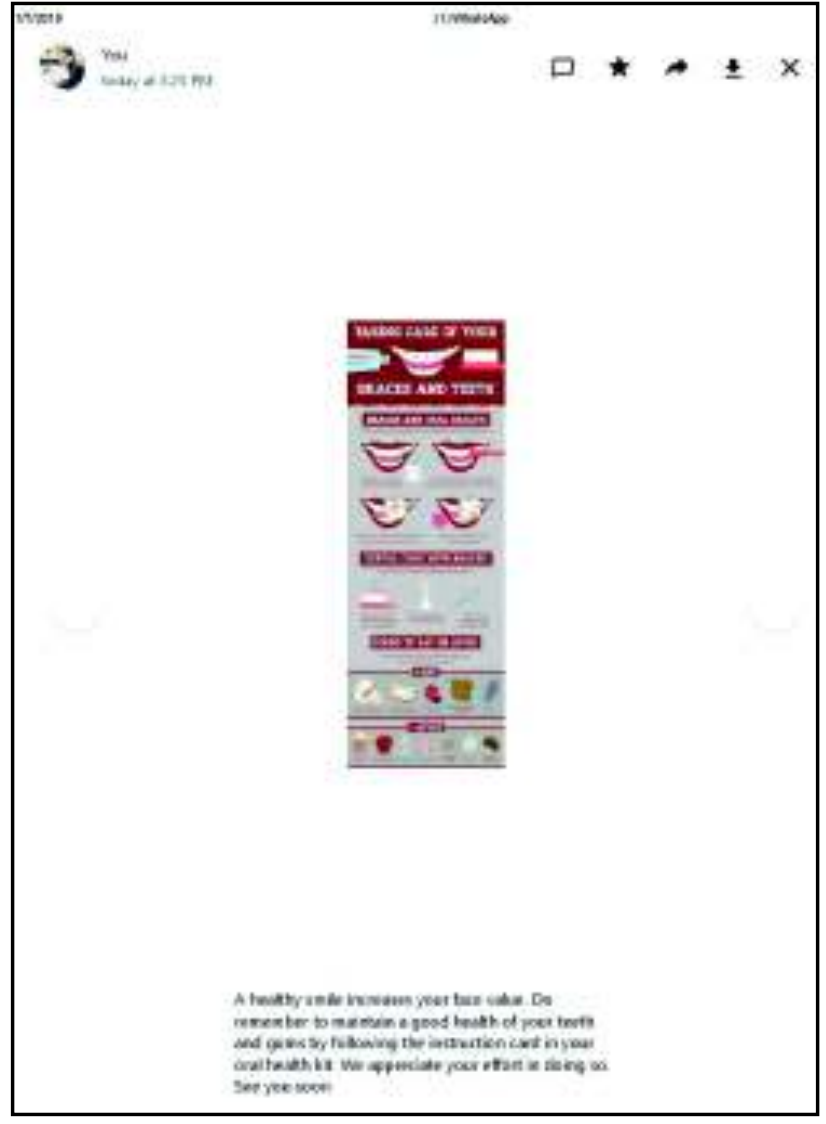

Figure 2: Treatment response for MGI over time.

$\mathrm{BI}$ is a strong indicator of oral hygiene compliance, as it has been shown to have high sensitivity and specificity in periodontal health evaluation. (Lang et al., 1990) (De Souza et al., 2003) In addition, MGI has demonstrated high sensitivity for assessing resolution and progression of gingivitis. (Barnett, 1996) Studies have indicated that MGI and BI correlate well and should produce comparable results when used together in a clinical trial. (Barnett, 1996) Therefore, significantly lower BI and MGI scores in the Whatsapp group at T2 should be viewed as strong evidence of its effectiveness in improving oral hygiene as compared to regular text messages over time.

\section{CONCLUSION}

The sending of whatssapp messages with a graphic content to patients explaining and reminding them of the importance of oral hygiene is a more effective way to maintain an improved oral hygiene during orthodontic treatment. 


\section{REFERENCES}

Atack N., Sandy J. and Addy M., 1996. Periodontal and microbiological changes associated with the placement of orthodontic appliances: a review. J. Periodontol., 67:78-85.

Alstad S. and Zachrisson B., 1979. Longitudinal study of periodontal condition associated with orthodontic treatment in adolescents. Am. J. Orthod. Dentofacial Orthop., 76:277-286.

Al-Jewair T. and Suri S., 2011. Predictors of adolescent compliance with oral hygiene instructions during two-arch multibracket fixed orthodontic treatment. Angle Orthod., 81: 525- 531.

Almog D., Devires J., Borrelli J. and KopyckaKedzierawski D., 2003. The reduction of broken appointment rates through an automated appointment confirmation system. J. Dent. Educ., 67:1016-1022.

Bollen A., Cunha-Cruz J., Bakko D., Huang G. and Hugoel P., 2008. The effects of orthodontic therapy on periodontal health: a systematic review of controlled evidence. J. Am. Dent. Assoc., 139:413-422.

Burket L., 1963. Effects of orthodontic treatment on the soft periodontal tissues. Am. J. Orthod. Dentofacial Orthop., 49:660-671.

Bratthall D., 1967. Programmed self-instruction in oral hygiene. J. Periodontol Res., 2:207-214.

Boyd R., 2007. Enhancing the value of orthodontic treatment: incorporating effective preventive dentistry into treatment. Am. J. Orthod Dentofacial Orthop., 17:601-603.

Bowen B., Rinchuse D., Zello T. and DeMaria M., 2015. The influence of text messaging on oral hygiene effectiveness. Angle Orthod. 85:543-548.

Barnett M.L., 1996. Suitability of gingival indices for use in therapeutic trails. Is bleeding a sine qua non? J. Clin. Periodontol., 23:582-586.

Cantekin K., Celikoglu M., Karadas M., Yildirim H. and Erdem A., 2011. Effects of orthodontic treatment with fixed appliances on oral health status: a comprehensive study. J. Dent. Sci., 6:235-238.

Casey G., 1988. Maintenance of oral hygiene and dental health during orthodontic therapy. Clin. Prev. Dent., 10:11-13.

Cole-Lewis H. and Kershaw T., 2010. Text messaging as a tool for behavior change in disease prevention and management. Epidemiol Rev., 32:56-69.

Can S., Marfarlane T. and O'Brien K., 2003. The use of postal reminders to reduce non-attendance at an orthodontic clinic: a randomized controlled trial. Br. Dent. J., 195:199-201.

Derks A., Kuijpers-Jagtman A., Frencken J., Van't Hof M. and Katsarose C., 2007. Caries preventive measures used in orthodontic practices: An evidence-based decision? Am. J. Orthod. Dentofacial Orthop., 132:165-170.

De Souza P.H., de Toledo B.E., Rapp G.E., Zuza E.P., Neto C.B. and Mendes A.J., 2003. Reliability of bleeding and non-bleeding on probing to gingival histological features. J. Int. Acad Periodontol., 5:71-76.

Eppright M., Shroff B., Best A., Barcoma E. and Lindauer S.J., 2014. Influence of active reminders on oral hygiene compliance in orthodontic patients. Angle Orthod., 84:208-213.

Feliu J., 1982. Long-term benefits of orthodontic treatment on oral hygiene. Am. J. Orthod., 82:473-477.

Fjeldson B., Marshall A. and Miller Y., 2009. Behavior change interventions delivered by mobile telephone short-message service. Am. J. Prev. Med., 45:184-198.

Fjeldsoe B., Marshall A. and Miller Y., 2009. Behavior change interventions delivered by mobile telephone short-message service. Am. J. Prev. Med., 36:165-173.

Foley J. and O'Neill M., 2009. Use of mobile telephone short message service (SMS) as a reminder: the effect on patient attendance. Eur. Arch Paediatr Dent., 10:15-19. 
MALIK ET. AL.: TO DETERMINE THE EFFECTIVENESS OF REMINDING PATIENTS IN MAINTAINING...

Hamilton J.Y., 2011. Orthodontists shd B txN Patients. The Progressive Orthodontist, 2:42-44.

Keith D., Rinchuse D., Kennedy M. and Zullo T., 2013. Effect of textmessage follow-up on patient's selfreported level of pain and anxiety. Angle Orthod. 83:605-610.

Lundstrom F., Hamp S. and Nyman S., 1980. Systematic plaque control in children undergoing long-term orthodontic treatment. Eur. J. Orthod., 2:27-39.

Lally P., Van Jaarsveld C., Potts H. and Wardle J., How habits are formed: modelling habit formation in the real world. Eur. J. So.

Lang N.P., Adler R., Joss A. and Nyman S., 1990. Absence of bleeding on probing. An indicator of periodontal stability. J. Clin. Periodontol., 17:714721.

Quigley G. and Hein J.W., 1962. Comparative cleansing efficiency of manual and power brushing. J. Am. Dent. Assoc., 65: 26-29.

Roth J., Kula T., Claros A. and Kula K., 2004. Effect of a computergenerated telephone reminder system on appointment attendance. Semin Orthod., 10:190193.
Saxton C.A. and van der Ouderaa F.J., 1989. The effect of a dentrifice containing zinc citrate and Triclosan on developing gingivitis. J. Periodontal Res., 24:7580 .

Schluger S., 1968. Periodontal aspects of orthodontic treatment. JPO J. Pract. Orthod., 5:111-117.

Sinha P., Nanda R. and McNeil D., 1996. Perceived orthodontist behaviors that predict patient satisfaction, orthodontistpatient relationship, and patient adherence in orthodontic treatment. Am. J. Orthod Dentofacial Orthop., 110: 370-377.

Skidmore K., Brook K., Thomson W. and Harding W., 2006. Factors influencing treatment time in orthodontic patients. Am. J. Orthod. Dentofacial Orthop., 129:230-238.

Zachrisson S. and Zachrisson B., 1972. Gingival condition associated with orthodontic treatment. Angle Orthod., 42:26-34.

Zachrisson B. and Alnaes L., 1973. Periodontal condition in orthodontically treated and untreated individuals, I: loss of attachment, gingival pocket depth and clinical crown height. Angle Orthod., 43:402-411. 